\title{
Environmental Lead Exposure and Male Infertility
}

\author{
Hanan L.Al-Omary PhD physiology*, Zainab M. Alawad MSc physiology*, \\ IsraaF. jaafar. PhD physiology* \\ *Physiology department/Medical College-Baghdad University.
}

\begin{abstract}
Summary:
Background: Lead ( $p b$ )is suspected to be one of the endocrine disruptors. People are exposed to high levels of it in the environment through several ways. In the last years there was an evidence that it affects semen quality. The aim of the study is to assess the level of lead in the blood of male patients and correlate it with the seminal fluid parameters and hormonal levels.

Methods: Fifty three infertile male patients, attending the infertility clinic in Baghdad Teaching Hospital from February 2016 till June 2016, participated in this study. Detailed history was taken and careful examination was done. Semen was collected from the patients and analyzed. Blood was withdrawn for hormonal and lead analysis.

Results: There was an increase in blood lead level with increasing age and duration of infertility which has a significant negative correlation with sperm count and hormonal levels ( $\mathrm{LH}$ and FSH), but it was not significant concerning sperm morphology.

There was no statistical significance between smokers and non-smokers regarding lead level and between those with primary and secondary infertility although it was higher in smokers and in patients with primary infertility.

Conclusion: Blood lead level affects male fertility since it has a negative impact on semen parameters including sperm count, in addition to the hormonal disturbance in those patients bringing LH and FSH towards low levels. Smoking on the other hand had been found to increase lead level in blood.
\end{abstract}

Keywords: Blood lead, seminal analysis, male infertility*

\section{Introduction}

In the last years, a growing concern has appeared about the correlation between environmental exposure to trace elements and the function of male reproductive system (1). People can be exposed to toxic pollutants like lead, cadmium, mercury and arsenic through intake of polluted food and water or contact with contaminated dust, soil, or air (2).Cigarette smoking and alcohol intake can also increase lead levels in blood and seminal plasma $(3,4,5)$. Deficiencies of dietary calcium, zinc and iron may increase lead level in blood as well $(6,7,8)$.

Workers are exposed to lead in many occupations, including motor vehicle assembly, panel beating, battery making, soldering, lead excavation and smelting, in glass, plastics, printing, ceramics, and paint industries (9). Exposure to lead happens primarily through respiratory and gastrointestinal systems and the ingested and absorbed lead will be stored mainly in soft tissue and bones (10).High blood lead levels can exert many negative impacts all over the body as lead can cause neuropsychological and functional decline, hepatotoxicity and cardiotoxicity $(11,12,13)$.

Previously, the diagnosis of lead toxicity was based on markedly high lead levels in blood. Nonetheless, currentliterature concludes that even low exposure to lead with low blood lead level (below 10 $\mu \mathrm{g} / \mathrm{dl}$ ) can cause neurological abnormalities, hypertension and renal problems (14).

Lead has negative impact on fecundity in both male and female. It has been found that blood lead level correlated negatively with fertilization rate in women undergoing assisted reproduction (15). Lead toxicity on the male reproductive system has been a major area of interest since several years as an important part of idiopathic infertility could be related to the exposure to toxic elements such as inorganic lead. The effect of lead on reproductive system seems to be complex and may involve multiple pathways (16).

However, a relatively small number of studies have addressed this impact of high blood lead level on male fecundity and they showed controversy about the mechanism of lead reproductive toxicity so this study was conducted in a trial to reveal this controversy.

\section{The aim of the study:}

The main goal of this study is to evaluate the correlation between seminal fluid characteristics (sperm count, motility and morphology) and the blood concentrations of lead. The secondary goal is to evaluate the correlation between blood lead level and hormonal levels (LH, FSH) in infertile male. 


\section{Materials and Methods}

Fifty three male patients were enrolled in the study, those who attended the infertility clinic in Baghdad Teaching Hospital, in the period between February 2016 and June 2016.Thorough history was taken from them including age, occupation, smoking, duration of marriage, duration of infertility, previous medical, and surgical history.

Male patients who were known to be diabetic or have varicocele, patients with orchitis, known congenital syndromes, or patients who were exposed to chemotherapy or radiation were excluded, in addition to those who had occupational exposure or who had taken any hormonal therapy. A questionnaire was arranged for demographic data such as age, duration of marriage and infertility, whether or not having occupational exposure, cigarette consumption (yes/no) and previous medical and surgical history.

After taking a consent from the patients, seminal fluid was collected from them for detailed analysis after 3 days of abstinence. Blood was collected for hormonal estimation (LH,FSH) after centrifuging it and it was freezed until the time of measurement, hormonal measurement was done using radioimmunoassay method. At the same time whole blood was drawn from the participants for lead estimation. In fact there is no normal amount of lead in blood because it does not constitute the human body. Small amounts of lead in adults are not believed to cause poisoning ( i.e levels of less than 10 micrograms $(\mu \mathrm{g})$ per deciliter (dl) of lead in the blood in adults and less than $5 \mu \mathrm{g} / \mathrm{dl}$ in children), but it can be harmful on the long term (17).

Blood lead measurement was done using lead care analyzer, which includes the lead care kit, and the lead care analyzer device version 3.3(ESA, INC,USA). Fifty micro liter of the whole blood in the EDTA tubes was drawn to be added to the treatment reagent in the special tubes supplied by the kit. The tubes were covered and the blood was mixed thoroughly with the reagent, until the color of the mixture became brown. Then the tubes were left to stand up for a minute allowing the mixture to drain down to the bottom of the tube. Using pipette, a 35 micro liter of the mixture was drawn and applied to the sensor of the device after calibration and the process of analysis was started.

\section{Data analysis}

All data were tabulated using Microsoft Excel and statistical analysis was made using SPSS 17.0 .All values were in mean $\pm \mathrm{SD}$ and using unpaired $t$ tests where appropriate. A P value of less than 0.05 was considered significant. The correlation between lead level and other parameters was tested using Pearson correlation test.

\section{Results}

Among the patients that have been enrolled in the study, twenty five males were smokers. Lead was measured in them and it was $28.62 \pm 21.33$ (mean $\pm \mathrm{SD}$ ) which was higher than its level in the non- smoker group $(13.59 \pm 10.78)$, but the difference was not significant (figure 1).

Figure (1): Lead Level in Smokers and Non- Smokers.

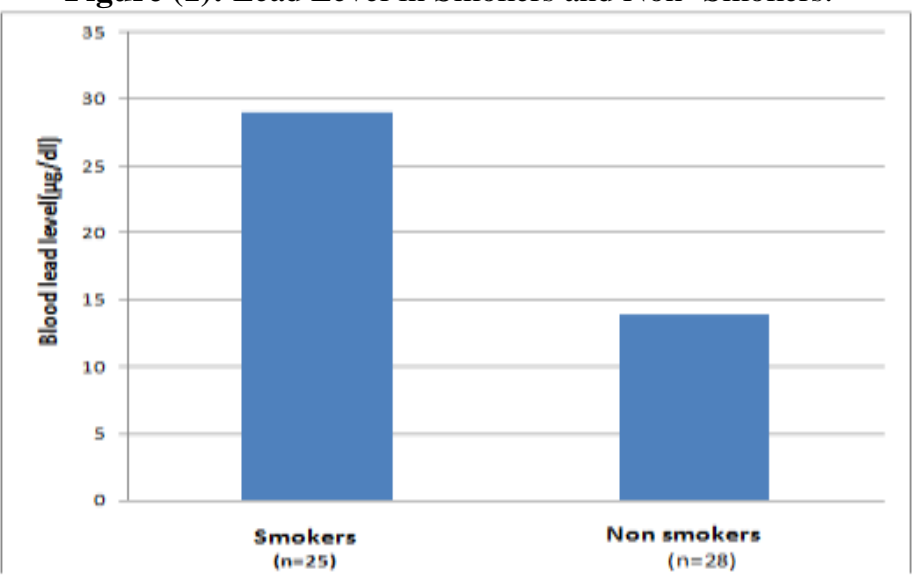

Lead level in patients with primary infertility was higher than its level in secondary infertility patients, but with no significant difference (table 1).

Table (1):Lead level in primary and secondary infertility patients.

\begin{tabular}{|l|l|l|l|}
\hline & Primary infertility $(\mathbf{n}=24)$ & Secondary infertility(n= 29) & P value \\
\hline Lead level $(\mu \mathrm{g} / \mathrm{dl})$ & $\mathbf{3 3 . 8 4} \pm \mathbf{2 7 . 1 3}$ & $\mathbf{3 0 . 8 4} \pm \mathbf{1 6 . 4 4}$ & $\square \mathbf{0 . 0 5}$ \\
\hline
\end{tabular}

Correlating the age with the lead level in all patients reviled a positive correlation. The older patients have higher lead levels in their blood (table 2). 
Table (2): Correlation between lead level and age of the patients.

\begin{tabular}{|l|l|l|}
\hline & \multicolumn{2}{|l|}{ Age (years) } \\
\cline { 2 - 3 } & r value & P value \\
\hline Lead level $(\mu \mathrm{g} / \mathrm{dl})$ & $\mathbf{0 . 1 0}$ & $\mathbf{0 . 0 5}$ \\
\hline
\end{tabular}

Sperm count was found to correlate negatively and significantly with lead level i.e with the increase in blood lead level there is decrease in sperm count per deciliter (figure 2). The same correlation but with no significant result was found regarding the morphology of sperms (table 3).

Figure (2): Correlation between lead level and sperm count.

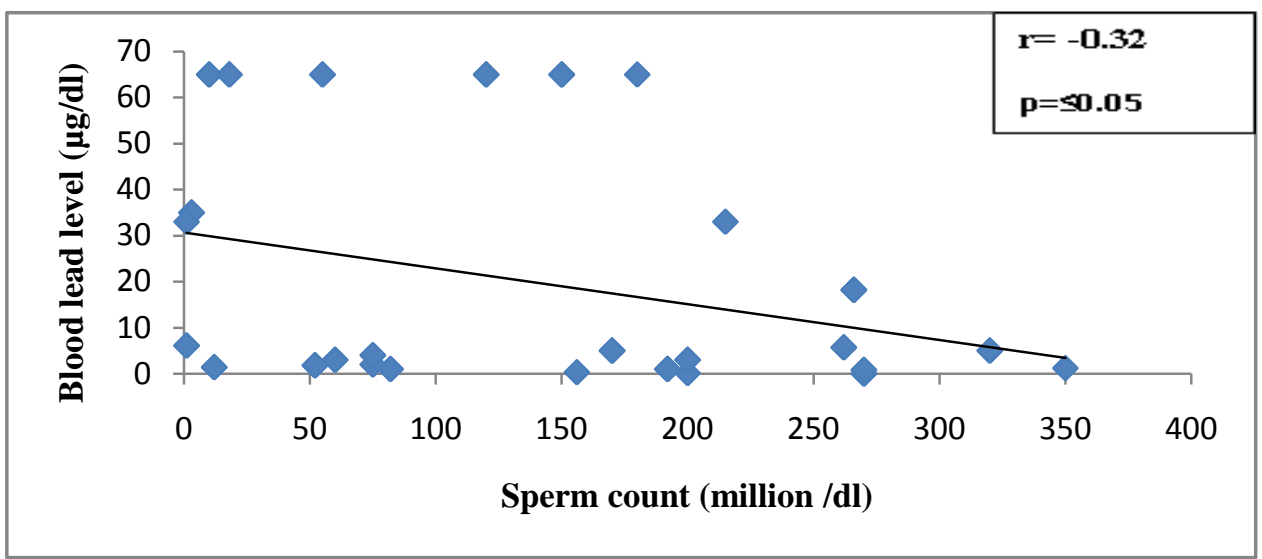

Table (3): Correlation between lead level and normal sperm morphology.

\begin{tabular}{|l|l|l|}
\hline & Normal morphology sperms \\
\cline { 2 - 3 } & r value & P value \\
\hline Lead level $(\mu \mathrm{g} / \mathrm{dl})$ & $-\mathbf{0 . 0 9}$ & $\square .05$ \\
\hline
\end{tabular}

The correlation between lead levels and the average motility in male patients was negative i.e increasing lead levels causes decline in general motility as shown in figure 3.

Figure (3): Correlation between lead level and average motility.

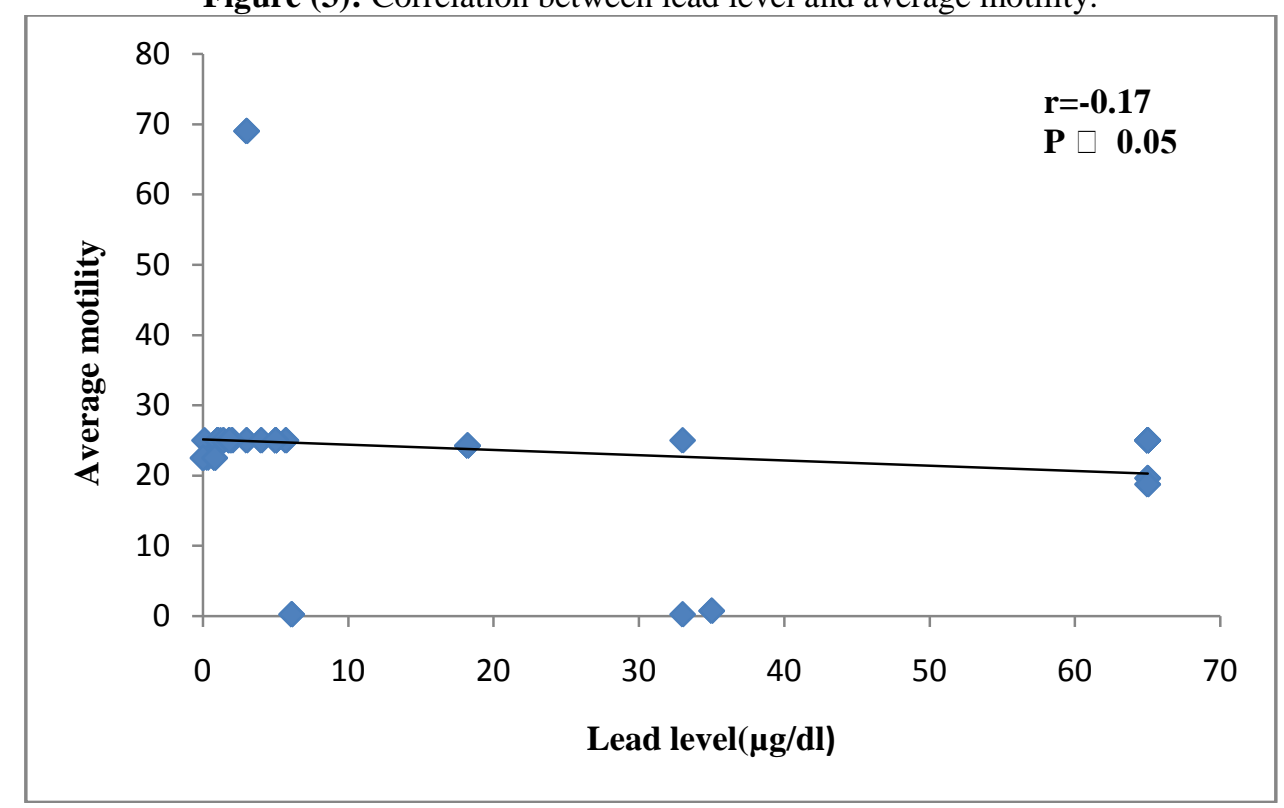

With the increase in blood lead level there was an increase in the duration of infertility and it was a significant positive correlation (figure 4). While table 4 and table 5 show a significant negative correlation between blood lead level and hormonal levels (LH and FSH). 
Figure (4): Correlation between lead level and the duration of infertility.

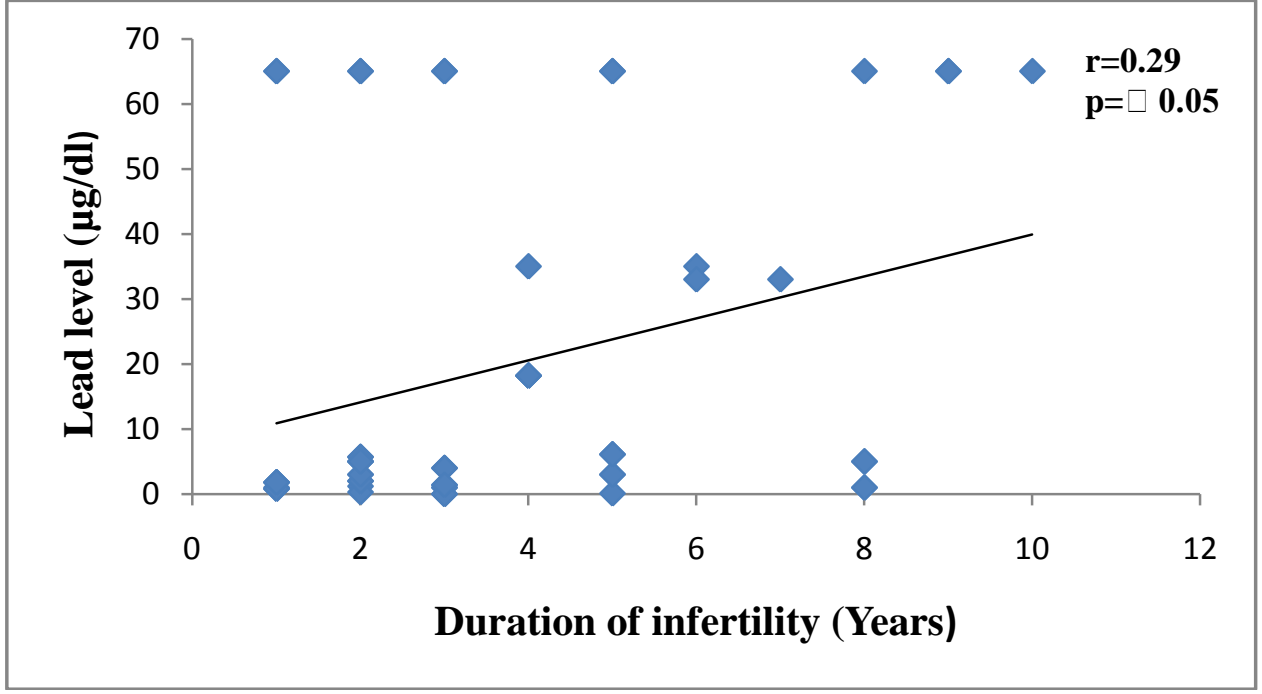

Table (4): Correlation between lead level and LH level.

\begin{tabular}{|l|l|c|}
\hline & \multicolumn{2}{|l|}{ LH level $(\mathrm{m}$ IU/ml) } \\
\cline { 2 - 3 } & r value & P value \\
\hline Lead level $(\mu \mathrm{g} / \mathrm{dl})$ & $\mathbf{- 0 . 6 8}$ & $\square .05$ \\
\hline
\end{tabular}

Table (5): Correlation between lead level and FSH level.

\begin{tabular}{|l|l|c|}
\hline & FSH level $(\mathrm{m}$ IU/ml $)$ \\
\cline { 2 - 3 } & r value & P value \\
\hline Lead level $(\mu \mathrm{g} / \mathrm{dl})$ & -0.70 & $\square .05$ \\
\hline
\end{tabular}

\section{Discussion}

Cigarette smoke has more than 7,000 chemicals, including lead which is involved in serious diseases in human (18) because it accumulates in the body tissues including testes in male(19). In fact active and passive smoking are sources of exposure to metals (20).This study investigated the level of lead in smoker patients, and it was found to be more than that in non- smokers. This can be explained by the fact that lead is a part of tobacco smoke, in addition to the environmental exposure to lead, this result is supported by the study of Mannino and his team who documented an increased lead level in current smokers than former ones or non- smokers. Even the passive smokers were found to have higher blood lead level than non- smokers $(21,22)$.Tobacco leaves absorb both radioactive and non-radioactive $(\mathrm{Pb}-210, \mathrm{~Pb}-206)$ lead from the air on their surface, due to the presence of trichomes (sticky hairs that trap and retain particles after rinsing with water). This is believed to be the main source of lead in tobacco (21).

Around $11 \%$ of lead from cigarettes enters the smoke, and about half of that is thought to enter the lungs of smokers. The major part of the remainder is found in the ash, though some pollute the environment, increasing the lead levels of dust in the households of smokers (23).

Another study was done measuring lead level in a group of smoking pregnant women and it was found to be higher than that in tobacco abstainers (24).

Patients with primary infertility had blood lead levels higher than those with secondary infertility. This result was in agree with a study done by Rahman and his team, who reported an increase chances of infertility in couples with high blood lead levels (25).It was found that sperm in high lead level semen were unable to bind perfectly to the egg or enhance the reaction needed to pass through the egg's covers (26).

With increasing age there is an increase in blood lead level, and this can be explained by the accumulation of lead over years not because of the routine environmental exposure only but because of the in home and secondary smoking environment that they live (27). On the other hand a study done by Bellinger reported that children aged 3 - 5 years had blood lead level higher than did older ones (aged 12-18 y) and young adults (aged 19 to $34 \mathrm{y}$ ),despite the fact that blood lead level indicates not only ongoing exposures but also lead stored in the body (28).

As an effect on semen parameters, sperm count appeared to decrease with the increase in lead level. Many studies on reproductive system of animals have reported lead as a toxic substance for testicular tissue and functions (29), including spermatogenesis and mature sperm formation(30).It was suggested that spermatogenesis regression is caused by increased inhibin B synthesis in highly lead exposed subjects (31). 
Many studies agree with this finding $(32,33,34,35)$ including a study which was done on mice and found that there is a significant decrease in the number of spermatozoa within the epididymis in mice exposed to lead acetate in drinking water (36), and prevent spermatogenesis in rats (37). On the other hand some researchers have failed to demonstrate such a correlation between lead and sperm count $(38,39)$.

Average sperm motility has been affected in a negative correlation with blood lead level as a part of the lead impairment on the sperm vitality which could be explained by the direct toxic effect of lead in seminal plasma (40).

The morphology of sperms is also affected by the increase in lead level as the normal sperms shapes decrease .This result goes with other studies demonstrating abnormal sperms in lead exposed patients, because of the replacement of lead for calcium as a second messenger, which leads to changes in protein conformation.(41,42). While Vigeh and his team related such effect to the concentration of lead in blood and the duration of exposure (16).

The increase in blood lead level has affected hormonal levels (LH and FSH )in a negative pattern ,which has an inverse influence on fertility in these patients since reproductive hormones play an important and complicated role in the regulation of spermatogenesis and sperm development. The results of experimental studies in rats have shown that lead affects multiple sites on male reproductive hormones although the most important part of these disorders may occur in the hypothalamic-pituitary-testosterone (HPT) axis $(43,44)$.In other studies, no changes were observed in androgen and gonadotropin levels (LH ,FSH) (45),since they did not establish a solid relationship between lead exposure and hormonal changes and sperm abnormalities. This fact makes it difficult to determine an absent effectora precise dose-response properties (46).Most of these studies explained their results by the fact that blood -testis barrier is thought to protect the testis from exposure to lead (16).Furthermore there are studies reporting an increase in male hormones on lead exposure (47).

Actually Leydig cells was found to have degeneration on histopathological examination in rats exposed and drank lead loaded water suggesting that this tissue is a target for lead intoxication (48).

\section{Conclusion}

Increasing blood lead level causes decrease and impairment in semen parameters in addition to hormonal disturbances in those patients bringing LH and FSH towards low levels. Smoking is found to increase lead level in blood of male patients.

\section{Author's Contribution:}

The aim of the study was designed by Dr.IsraaF.jaafar .Collection of data, processing and writing of the study was achieved by Dr.Hanan Luay and Dr. Zainab Muthana.

\section{References}

[1] Pasqualotto FF, Lucon AM, Sobreiro BP, Pasqualotto EB, Arap S. Effects of medical therapy, alcohol, smoking, and endocrine disruptors on male infertility. Revista do Hospital das Clínicas. 2004;59(6):375-82.

[2] Meeker JD, Rossano MG, Protas B, Diamond MP, Puscheck E, Daly D, Paneth N, Wirth JJ. Cadmium, lead, and other metals in relation to semen quality: human evidence for molybdenum as a male reproductive toxicant. Environmental health perspectives. 2008 Nov 1;116(11):1473.

[3] Kiziler AR, Aydemir B, Onaran I, Alici B, Ozkara H, Gulyasar T, Akyolcu MC. High levels of cadmium and lead in seminal fluid and blood of smoking men are associated with high oxidative stress and damage in infertile subjects. Biological trace element research. 2007 Dec 1;120(1-3):82-91.

[4] Dally S, Girre C, Hispard E, Thomas G, Fournier L. High blood lead level in alcoholics: wine vs. beer. Drug and alcohol dependence. 1989 Jan 31;23(1):45-8

[5] Grandjean P, Olsen NB, Hollnagel H. Influence of smoking and alcohol consumption on blood lead levels. International archives of occupational and environmental health. 1981 Aug 1;48(4):391-7.

[6] Turgut S, Polat A, Inan M, Turgut G, Emmungil G, Bican M, Karakus TY, Genç O. Interaction between anemia and blood levels of iron, zinc, copper, cadmium and lead in children. The Indian Journal of Pediatrics. 2007 Sep 1;74(9):827-30.

[7] Mahaffey KR. Nutritional factors and susceptibility to lead toxicity. Environmental health perspectives. 1974 May;7:107.

[8] Goyer RA. Nutrition and metal toxicity. The American journal of clinical nutrition. 1995 Mar 1;61(3):646S-50S

[9] Tong S, Schirnding YE, Prapamontol T. Environmental lead exposure: a public health problem of global dimensions. Bulletin of the World Health Organization. 2000 Jan;78(9):1068-77.

[10] Mudipalli A. Lead hepatotoxicity \& potential health effects. Indian Journal of Medical Research. 2007 Dec 1;126(6):518

[11] Mason LH, Harp JP, Han DY. Pb neurotoxicity: neuropsychological effects of lead toxicity. BioMed research international. 2014 Jan 2;2014.

[12] Prentice RC, Kopp SJ. Cardiotoxicity of lead at various perfusate calcium concentrations: functional and metabolic responses of the perfused rat heart. Toxicology and applied pharmacology. 1985 Dec 31;81(3):491-501.

[13] Kumar MR, Reddy KS, Reddy AG, Reddy RA, Anjaneyulu Y, Reddy DG. Lead-induced hepatotoxicity and evaluation of certain anti-stress adaptogens in poultry. Toxicology international. $2011 \mathrm{Jan} ; 18(1): 62$

[14] Patrick L. Lead toxicity, a review of the literature. Part I: exposure, evaluation, and treatment. Alternative Medicine Review. 2006 Mar 1;11(1):2-3.

[15] Al-Saleh I, Coskun S, Mashhour A, Shinwari N, El-Doush I, Billedo G, Jaroudi K, Al-Shahrani A, Al-Kabra M, Mohamed GE. Exposure to heavy metals (lead, cadmium and mercury) and its effect on the outcome of in-vitro fertilization treatment. International journal of hygiene and environmental health. 2008 Oct 1;211(5):560-79. 
[16] Vigeh M, Smith DR, Hsu PC. How does lead induce male infertility?. Iranian journal of reproductive medicine. 2011;9(1):1-8.

[17] Kao LW, Rusyniak DE: Chronic poisoning: trace metals and others. In: Goldman L, Schafer AI, eds.Goldman's Cecil Medicine. 25th ed. Philadelphia, PA: Elsevier Saunders;:chap 22. 2016.

[18] Rodgman A, Perfetti TA: The chemical components of tobacco and tobacco smoke. Boca Raton (FL): CRC Press; p. 1259. 2008

[19] Mortensen ME, Wong LY, Osterloh JD. Smoking status and urine cadmium above levels associated with subclinical renal effects in US adults without chronic kidney disease. International journal of hygiene and environmental health. 2011 Jul 31;214(4):305-10.

[20] Apostolou A, Garcia-Esquinas E, Fadrowski JJ, McLain, RN P, Weaver VM, Navas-Acien A. Secondhand tobacco smoke: a source of lead exposure in US children and adolescents. American journal of public health. 2012 Apr;102(4):714-22.

[21] Mannino DM, Homa DM, Matte T, Hernandez-Avila M. Active and passive smoking and blood lead levels in US adults: data from the Third National Health and Nutrition Examination Survey. Nicotine \& tobacco research. 2005 Aug 1;7(4):557-64

[22] Liou SH, Wu TN, Chiang HC, Yang GY, Yang T, Wu YQ, Lai JS, Ho ST, Lee CC, Ko YC, Ko KN. Blood lead levels in Taiwanese adults: distribution and influencing factors. Science of the total environment. $1996 \mathrm{Feb} 23 ; 180(3): 211-9$.

[23] Galażyn-Sidorczuk M, Brzóska MM, Moniuszko-Jakoniuk J. Estimation of Polish cigarettes contamination with cadmium and lead, and exposure to these metals via smoking. Environmental monitoring and assessment. 2008 Feb 1;137(1-3):481-93.

[24] Chełchowska M, Jabłonka-Salach K, Ambroszkiewicz J, Maciejewski T, Gajewska J, Bulska E, Laskowska-KlitaT,Leibschang J, Barciszewski J. Effect of cigarette smoking on blood lead levels in pregnant women. Medycynawiekurozwojowego. 2011 Dec;16(3):196-204.

[25] Rahman SN, Fatima P, Chowdhury AQ, Rahman MW. Blood level of lead in women with unexplained infertility. Mymensingh medical journal: MMJ. 2013 Jul;22(3):508-12.

[26] Human Reproduction, Feb. 6, 2003, First Clues That Even Low Lead Levels Harm Sperm. http://www.webmd.com/men/news/20030206/lead-linked-to-male-infertility.

[27] King BA, Peck RM, Babb SD. Cost savings associated with prohibiting smoking in US subsidized housing. American journal of preventive medicine. 2013 Jun 30;44(6):631-4.

[28] Bellinger DC. Very low lead exposures and children's neurodevelopment. Current opinion in pediatrics. 2008 Apr 1;20(2):172-7.

[29] Hsu PC, Chen MY, Guo YL. Lead-induced changes in spermatozoa function and metabolism. Journal of Toxicology and Environmental Health Part A. 1998 Sep 1;55(1):45-64.

[30] Teijon C, Olmo R, Blanco D, Romero A, Teijon JM: Low doses of lead: effects on reproduction and development in rats. Biol Trace Elem Res. $2006 ; 111: 151-165$

[31] Mahmoud A, Kiss P, Vanhoorne M, De Bacquer D, Comhaire F. Is inhibin B involved in the toxic effect of lead on male reproduction?. International journal of andrology. 2005 Jun 1;28(3):150-5.

[32] Carlsen E, Giwercman A, Keiding N, Skakkebæk NE. Evidence for decreasing quality of semen during past 50 years. Bmj. 1992 Sep 12;305(6854):609-13.

[33] Apostoli P, Kiss P, Porru S, Bonde JP, Vanhoorne M. Male reproductive toxicity of lead in animals and humans. ASCLEPIOS Study Group. Occupational and Environmental Medicine. 1998 Jun 1;55(6):364-74.

[34] Alexander BH, Checkoway H, Faustman EM, van Netten C, Muller CH, Ewers TG. Contrasting associations of blood and semen lead concentrations with semen quality among lead smelter workers. American journal of industrial medicine. 1998 Oct 1;34(4):464-9.

[35] Nathan E, Huang HF, Pogach L, Giglio W, Bogden JD, Seebode J. Lead acetate does not impair secretion of Sertoli cell function marker proteins in the adult Sprague Dawley rat. Archives of Environmental Health: An International Journal. 1992 Oct $1 ; 47(5): 370-5$

[36] Wadi SA, Ahmad G. Effects of lead on the male reproductive system in mice. Journal of Toxicology and Environmental Health Part A. 1999 Mar 25;56(7):513-21.

[37] Batra N, Nehru B, Bansal MP. Influence of lead and zinc on rat male reproduction at 'biochemical and histopathological levels'. Journal of Applied Toxicology. 2001 Nov 1;21(6):507-12

[38] Telišman S, Colak B, Pizent A, Jurasović J, Cvitković P. Reproductive toxicity of low-level lead exposure in men. Environmental research. 2007 Oct 31;105(2):256-66.

[39] Bonde JP, Joffe M, Apostoli P, Dale A, Kiss P, Spano M, Caruso F, Giwercman A, Bisanti L, Porru S, Vanhoorne M. Sperm count and chromatin structure in men exposed to inorganic lead: lowest adverse effect levels. Occupational and Environmental medicine. 2002 Apr 1;59(4):234-42.

[40] Al-Juboori BM, Hamdan FB, Al-Salihi AR. Effect of Low-dose Lead on Semen Quality and Sperm's DNA Integrity in Adult Male Mice. Central European Journal of Experimental Biolog2013;2 (3):4-14.

[41] Willems MI, De Schepper GG, Wibowo AA, Immel HR, Dietrich AJ, Zielhuis RL. Absence of an effect of lead acetate on sperm morphology, sister chromatid exchanges or on micronuclei formation in rabbits. Archives of toxicology. 1982 Jul 1;50(2):149-57.

[42] Brochin R, Leone S, Phillips D, Shepard N, Zisa D, Angerio A. The Cellular Effect of Lead Poisioning and Its Clinical Picture. Issues. 2008 Dec;5(2).

[43] Ronis MJ, Badger TM, Shema SJ, Roberson PK, Shaikh F. Reproductive toxicity and growth effects in rats exposed to lead at different periods during development. Toxicology and applied pharmacology. 1996 Feb 29;136(2):361-71.

[44] Sokol RZ, Madding CE, Swerdloff RS. Lead toxicity and the hypothalamic-pituitary-testicular axis. Biology of reproduction. 1985 Oct 1;33(3):722-8.

[45] Fischbin A. Occupational and environmental exposure to lead: In: Rom WN, editor. Environmental occupational medicine. 3rd Ed. Philadelphia: Lippincott-Raven. 1998.

[46] El-Zohairy EA, Youssef AF, Abul-Nasr SM, Fahmy IM, Salem D, Kahil AK, Madkour MK. Reproductive hazards of lead exposure among urban Egyptian men. Reproductive Toxicology. 1996 Apr 30;10(2):145-51.

[47] Gustafson A, Hedner P, Schütz A, Skerfving S. Occupational lead exposure and pituitary function. International archives of occupational and environmental health. 1989 Feb 1;61(4):277-81.

[48] Saxena DK, Hussain T, Lal B, Chandra SV. Lead induced testicular dysfunction in weaned rats. Industrial health. 1986;24(2):105-9. 